\title{
Application of Artistic Elements in Costume Design Ke Wang
}

\author{
Qiong Tai Normal University 571100
}

Keywords: Costume; Design; Artistic element

\begin{abstract}
Costume design is a process of combing design process with the application of art. The effect of art on costume design is profound. Rational use of various artistic elements in costume design cannot only enhance the beauty of costumes, but also plays an indispensable role in arousing designers' creation inspiration.

In today's society, clothing is not only used to cover the body, but is embodied with more profound meaning. As the saying goes: dress for the job you want, not the job you have. Nowadays, with the rapid economic and social development, people love beauty, pursue beauty and fashion.

Clothing plays an important role in people's pursuit of beauty. Beautiful clothes can shape the beauty of human body and bring out the beauty of human gesture and grace, etc. Therefore, everyone who pursues beauty is inseparable from clothing. "Clothes make the man, or horse by saddle", "thirty percentage of natural appearance and seventy percentage of external clothing make a beautiful person" and other proverbs indicate the importance of clothing beauty. The history of the development of human civilization, from a certain extent, can also be understood as the history of human clothing.

In the commodity economy, the attribute of clothing as commodity is becoming increasingly prominent, which proposes higher requirements for costume design and determines that only beautiful, good products in line with the public's aesthetic demands or surpasses the general aesthetics can stand out and occupy an indomitable place in the market. Costume design is the most crucial link of clothing from the concept to production. Good design ideas and concepts determine the taste and the success or failure of costume in the beginning. The application of artistic elements plays a decisive role in costume design. Rational and reasonable combination of art elements and costume design plays an indispensable role in improving the beauty of clothes and stimulating design inspiration.
\end{abstract}

\section{Relationship between Costume Design and Art}

Costume design is a creative process, its development process and historical process are synchronized. In different historical periods, social, economic, technical level and so will affect and constrain the concept of costume design. Costume design may be no stranger for each person, especially for women, who are quite familiar with the color, fabric, tailoring, style, etc. In the rapid development of the times and society, people's understanding of the costume design is constantly changing. More and more attention is paid to the artistic elements in the costume design, and people expect more and more artistic elements in different garments.

The beauty of costume design is not just material, but also the spiritual beauty. Costume design must serve for life but cannot exist independently and be isolated from life. This attribute determines the costume design must meet the material and spiritual needs of the people. No matter how the evolution of society, the evolution of art is always accompanied by the development of the design to show a new force. The combination of art and design can create more perfect costume design products. For example, a suit is not just a suitable coat, but it is a design concept and artistic idea. While choosing a commodity, in addition to the usage value of goods itself, people pay attention to the aesthetic taste of goods and design ideas. Thus, costume design cannot be separated from the sensible artistic beauty, must also be designed to show the inherent strength of art. 
Art and design have always been inseparable. Compared to other forms of art, the influence of painting art on costume design is more direct and far-reaching. At the fashion week's conference, we can see a lot of master's design works are drawn from the painting inspiration. Designers will integrate fashion elements in painting and art works into costume design and gain unusual visual effects.

\section{Artistic Elements in Costume Design}

Art elements are a concept covering a wide range. As long as it is used properly, any artistic form of the elements can be used as costume design in the artistic elements. For example, the Chinese traditional Beijing opera in the face modeling, the only form of art, the face appears in the Peking opera and then naturally. But we cannot say that this artistic element can only be made in the Peking opera. In many cultural shirt or intended to reflect the elements of Chinese cultural elements, Facebook is widely used. In the international fashion week, Facebook has been widely adopted as a cultural and artistic symbol. The introduction of this art element into costume design is both a bold attempt and a fashion innovation. It shows that the costume design should not only use the inherent artistic elements, but should be bold and innovative.

Art elements have no boundaries, and each creator's understanding of artistic elements may be different. For Chinese designers, the history of China's five thousand years of up and down for their artistic creation to provide inexhaustible treasures. Chinese traditional art elements are numerous and rich in content. The traditional art elements are the most distinctive imprints of Chinese traditional culture. Although the structure is reorganized and the style is changing, it is all related to life. From the Neolithic pottery to the Shang and Zhou Dynasties bronze lines, and then to the Warring States period of light vessels, are in graphics, text and modeling, etc. reflects the charm of traditional Chinese art elements. With the passage of time, historical changes, these aspects become the main carrier of traditional Chinese art elements, embodies the wisdom and hope of the Chinese nation for thousands of years, and inherited the artistic spirit of the Divine Land.

Costume design itself is a process of art processing, and the various art forms are interlinked. China as a new developing country, in the field of costume design more and more foreign counterparts' attention. Chinese designers focus on the combination of traditional Chinese artistic elements and costume design, and create a lot of peer recognition works.

For example, ink painting is a very important part of traditional Chinese art, with unique aesthetic charm. Ink elements to bring the modern costume design rich material and inspiration, is the Chinese costume designer to use more of an artistic element. Designers use ink art elements to create a very Chinese style of clothing, so that traditional Chinese culture in the inheritance and development of a new breakthrough. The application of ink art element dress not only satisfies the pursuit of consumers' beauty, but also gives the fresh vitality of this traditional art of ink painting.

Traditional Chinese art forms emphasize the atmosphere. Especially, there are a lot contents with auspicious contents, and such aspiration for good things is often completed in the form of graphics. In the traditional Chinese art culture, the auspicious festive pattern is wide, including politics, economy, literature, history, religion and so on. These patterns and symbols are given positive and meaningful connotation and meaning. In the costume design with the Chinese cultural background, how can we combine the artistic elements of Chinese characteristics with the design and create a refreshing costume is a realistic problem that needs to be solved in front of each designer. We encourage the application of different artistic elements to costume design, but this introduction should be reasonable, rather than simply mechanically, should meet the minimum aesthetic standards, in line with the public's aesthetic pursuit; this introduction should be coordinated, rather than simple superposition and merely for the purpose of introduction, and various elements should not exclude each other. 


\section{It is Necessary to Follow the Principle of Combing Artisticity with Practicality}

Clothing in the final analysis is a consumable, and it generates in order to meet people's needs, which requires us to follow both artistic and practical principles in costume design. The so-called practicality is to meet people to protect the body, work, life needs, to adapt to a variety of ceremonial occasions, the needs of the season; the so-called art is based on the basic wear with the United States feel. Clothing is a tangible real product, it exists in people living in various fields. Since clothing is a tangible kind, in today's society, it should have the beauty of the property.

How to better combine the artisticity and practicality of clothing to serve the market economy and benefit customers and thus promote the ever-changing economic prosperity of the entire clothing industry is a problem worth pondering. Among them, it is particularly important to get to know the market, the society and customers' psychological demands. From the spiritual point of view of clothing, people's pursuit of beauty is human instinct, but also shared by the characteristics of mankind. As the saying goes: "Everyone has the heart to pursue beauty". However, people have different standards in the pursuit of beauty, just as the art of "elegant" "vulgar" tours the same; people in their social status, occupation, education and other differences in the pursuit of clothing beauty is also Different, which is leading to the classification of clothing, cultural tastes, different levels of the main reasons for positioning.

In costume design, both practicality and artisticity should be harmonized and cannot be neglected. Clothing is both human beings to survive and create a material condition, but also one of the spiritual elements of human development. This constitutes the duality of clothing, material is the basis for the existence of clothing, spiritual performance in its aesthetic and artistic. The spirit of clothing is based on materiality, spirituality is the material continuation and sublimation.

\section{Combination of Art with Business in Costume Design}

In the industrialization of costume design, business and art are two very important aspects. From the beginning of design, a clothing cannot be separated from the impact of commercial factors. Art is a concept that cannot be touch and must be shown through real products. And the success of the actual product sales is in separable from commercial operation. In a sense, costume design is a commodity manufacturing process in which artistic technique are used to create value. The designers use artistic techniques to express their own design concept and then interpret and control the business process later. Of course, the process of artistic creation plays a vital role in the success of business. A good costume designer has a correct understanding of the produce design in the beginning, and such understanding is not only about the product itself, but the clothing's property as goods should also be considered. In the absence of either of them, the design cannot achieve great success. Art and business should go together in design. Art should obey business but art itself should be independent.

\section{Conclusion}

Costume design needs inspiration, and the sources of inspiration are often pluralistic. In costume design, we need to pay attention to the many attributes of clothing, so it is necessary to resolve contradictions in innovation. As a designer, we must continue to learn and constantly expand our horizons, contact different cultures and appreciate different design styles and learn the ability to master a variety of artistic elements. In costume design, it is necessary to organically combine social aesthetics with individual aesthetics and constantly innovate concepts so as to form a unique and distinct design style. 


\section{References}

[1] SHEN Congwen, History of Chinese Clothing [M]. Xi'an: Shaanxi Normal University Press, May 2004

[2] ZHOU Xibao, History of Ancient Chinese Clothing [M]. Beijing: China Drama Publishing House, October 1986

[3] HUA Mei, Clothing Folklore [M]. Beijing: China Textile Publishing House, October 2004

[4]HUANG Nengfu, CHEN Juanjuan, History of Chinese Clothing [M]. Shanghai: Shanghai People's Publishing House, September 2004

[5] LI Dangqi, Introduction to Clothing [M]. Beijing: Higher Education Press, April 1990

[6] LI Dangqi, Western Clothing History [M]. Beijing: Higher Education Press, September 1995

[7] WANG Shouzhi, World Clothing History [M]. Beijing: China Youth Publishing House, 2002

[8] ZHANG Jingqiong, CAI Yi, Comparison between Chinese and Foreign Clothing [M]. Shanghai: China Textile University Press, June 2000

[9] YE Lichen, Clothing Aesthetics [M]. Beijing: China Textile Publishing House, November 2001 [10] (British) Edward L. Smith, World Industrial History [M]. Hangzhou: Zhejiang Academy of Fine Arts Publishing House, June, 1992

[11] QIN Mengna, Chinese Painting Culture [M]. Beijing: Current Affairs Press, 2008: 97-158.

[12] HU Meifang Elements and Ideas of National Costume [M]. Chongqing: Southwest Normal University Press, 2002: 154-176.

[13] GONG Liuchao, Foundation of Design [M]. Shijiazhuang: Huashan Literature and Art Publishing House, 2002: $98-124$. 